\title{
A systematic review of the relationship between acute tubular necrosis and kidney transplantation
}

\author{
Arezo Elmi $^{\circledR}$, Mohammad Arabsorkhi Mishabi ${ }^{\circledR}{ }^{\circledR}$, Esmaeil Teymoori $^{2}{ }^{\circledR}$, Dorrin Nikbakht $^{{ }^{\circledR}}$, Nazanin \\ Sarraf $^{2}$, Fatemeh Jabinian ${ }^{3}$, Abbas Khalilpour ${ }^{\mathbb{D}}$, Afsaneh Askarkhah ${ }^{4}$, Vahid Rahmani ${ }^{5,2^{*}}$
}

\author{
${ }^{1}$ Shohada Educational Hospital, Tabriz University of Medical Sciences, Tabriz, Iran \\ ${ }^{2}$ Department of Operating Room, Iran University of Medical Sciences, Tehran, Iran \\ ${ }^{3}$ Department of Operating Room, Shahid Sadoughi University of Medical Sciences, Yazd, iran \\ ${ }^{4}$ Department of Operating Room, Guilan University of Medical Sciences, Rasht, Iran \\ ${ }^{5}$ Department of Operating Room, Maragheh University of Medical Sciences, Maragheh, Iran
}

\section{A R T I CLE IN F O}

Article Type:

Review

\section{Article History:}

Received: 4 April 2020

Accepted: 9 July 2020

Published online: 13 August 2020

\section{Keywords:}

Acute tubular necrosis

Acute kidney injury

Kidney transplantation

Cyclosporine

\begin{abstract}
A B S T R A C T
Introduction: Acute tubular necrosis (ATN) is a common syndrome following kidney transplantation. In this study, we reviewed systematically the relationship between ATN and kidney transplantation.

Materials and Methods: International databases including PubMed, Web of Science and Scopus were considered for search of English articles by Aug 2019. Seven published articles were finally entered into the study. Keywords were ATN, acute kidney injury, kidney transplantation and renal transplantation or a combination of them in the title/abstracts.

Results: There were seven published articles (conducted on 2,534 individuals) reviewed in this systematic review consisted of two retrospective, three prospective studies and two clinical trial studies.

Conclusion: The administration of cyclosporine immediately following kidney transplantation is a predicting factor for development of ATN. According to the results, ATN can be associated with kidney transplantation, especially transplanted from deceased donors.
\end{abstract}

Implication for health policy/practice/research/medical education:

Administration of cyclosporine immediately following kidney transplantation is a predicting factor for development of acute tubular necrosis.

Please cite this paper as: Elmi A, Arabsorkhi Mishabi M, Teymoori E, Nikbakht D, Sarraf N, Jabinian E, et al. A Systematic review of the relationship between acute tubular necrosis and kidney transplantation. J Renal Inj Prev. 2021; 10(3): e18. doi: 10.34172/jrip.2021.18.

\section{Introduction}

Acute tubular necrosis (ATN) is a complex syndrome characterized by a rapid decrease in glomerular filtration rate and consequently retention of metabolic wastes (1). The causes of ATN are multifactorial, which include age of more than 60 years, chronic kidney disease, diabetes mellitus, and length of surgery. Nowadays, due to the high prevalence of ATN and its detrimental effects on body, a great deal of researches to determine the complications of the ATN was conducted. However, few effective modalities for the prevention of the ATN following kidney transplantation were existed. Although the use of calcium blockers, E12 (prostaglandins), theophylline, dopamine, intercellular adhesion molecules, platelet activating factor, alpha melanocyte-type activating hormone has been repeatedly suggested, no significant results have been obtained (2-9). As mentioned, the length of surgery is associated with the ATN, therefore kidney transplantation is prone to encounter with the ATN. Kidney allograft has some complications such as ATN, rejection of transplantation, allergy, infection and cyclosporine toxicity $(10,11)$. In this study, we reviewed systematically the relationship between ATN and kidney transplantation.

\section{Methods}

Search strategy

In this systematic review, international databases 
including PubMed, Web of Science and Scopus were considered for search of English articles by August 2019. All type of articles was included but case series less than five cases report were excluded. Keywords were as following; acute tubular necrosis, acute kidney injury, kidney transplantation, renal transplantation. Sample of search strategy for PubMed can be found in the following sentence.

((((Acute tubular necrosis [MeSH Terms]) OR Acute tubular necrosis [Title/Abstract]) OR acute kidney injury [Title/Abstract]) AND ((((Kidney Transplantation [MeSH Terms]) OR Kidney Transplantation [Title/Abstract]) OR Renal Transplantation [Title/Abstract])) AND (“1980/01/01”[PDat]: “2019/07/31”[PDat]))

After collection of articles of interest, references imported to Endnote software and removed duplicate titles. Then, after browsing titles, studies with irrelevant purposes were removed, and then the remaining studies assessed by two independent investigators. The selected studies were performed on humans and published in English.

\section{Data extraction}

Information dealing with the selected articles (the author's last name, year of publication, study design, sample size and the results of each article were taken by two independent investigators. The differences observed in this process corrected by a third investigator who was independent with the two previous investigators.

\section{Results}

There were seven published articles (conducted on 2534 individuals) considered in this systematic review which consisted of two retrospective, three prospective studies and two clinical trial investigations. We used the Preferred Reporting Items for Systematic Reviews and MetaAnalyses (PRISMA) checklist, a checklist of items that should be included in reports of interventional studies for selected articles $(12,13)$. The selection process using the PRISMA statement can be seen in Figure 1. The summary of the selected articles was shown in Table 1.

\section{Discussion}

Evidence shows that ATN is the most common cause of graft failure for up to $50 \%$ of transplanted kidneys following the use of cyclosporine $(21,22)$. Hypoperfusion, cold ischemia times, harvesting, anastomosis, surgical approach and the administration of cyclosporine following renal transplantation are revealed by now about the etiologic causes of $\operatorname{ATN}(23,24)$. Oliguria caused by ATN lasts for two months. In some cases it lasts more than two months and exceeds three months (25). Prolonged ATN happens while cyclosporine is used following kidney transplantation (26). In this regard, the administration

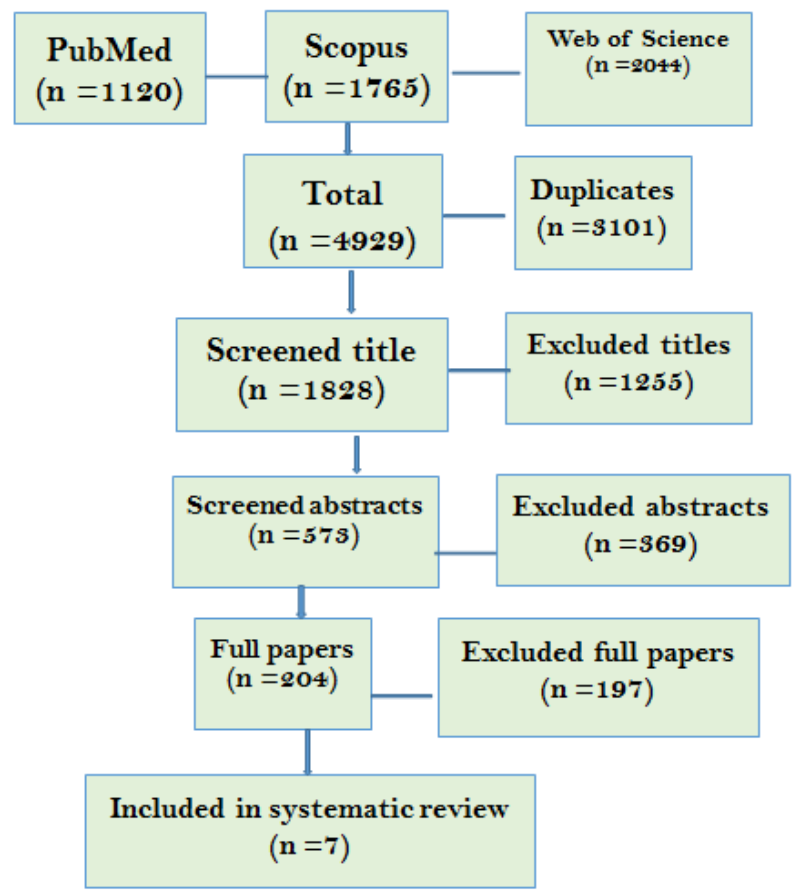

Figure 1. Flow chart of study selection based on PRISMA.

of calcium channel blockers can preserve the acute renal vasoconstriction following the use of cyclosporine $(27,28)$. ATN following kidney transplantation accounts for $90 \%$ of acute renal failures which happens within the first weeks after transplantation. It is worthy to be noted that ATN is observed in cadaver transplant recipients in up to $40 \%$ of cases. The etiology of ATN is not well-understood. When ATN occurred, patients must undergo daily dialysis and the dose of cyclosporine must be decreased by $50 \%$ (29). In the study of Garcia et al, ATN was reported following enalapril administration in two cases. In these two cases, ATN occurred after the administration of cyclosporine-A and also angiotensin-converting enzyme inhibitor (ACEI) to manage hypertension (30). Actually, more reported ATN can be observed among kidney transplantations of deceased donors; hence, it is an effective factor to predict ATN following kidney transplantation (31). In fact, the science of transplantation is young still and needs more research because of its importance and its multiple factors affecting main outcomes related to the health of patients. In the study by Mekeel et al, the effect of rhabdomyolysis was investigated and concluded that rhabdomyolysis is not a contraindication for performing kidney transplantation (32).

\section{Conclusion}

According to the results, ATN can be associated with kidney transplantation, especially transplanted from deceased donors. As well as, administration of cyclosporine immediately following kidney transplantation is a predicting factor for the development of ATN. 
Table 1. The detail of reviewed articles in this systematic study

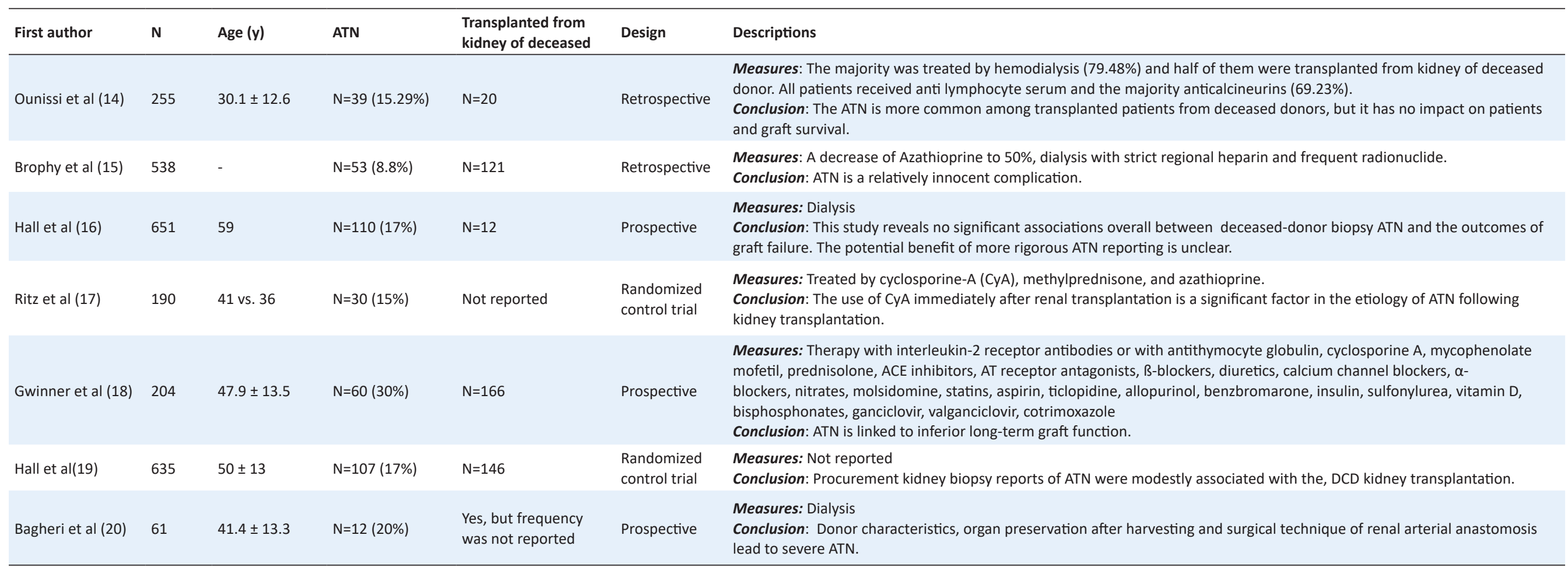




\section{Authors' contribution}

$\mathrm{AE}, \mathrm{MAM}$ and VR were the principal investigators of the study. VR, DN, NS, RMH and AK were included in preparing the concept and design. RMH, FJ, ET and AA revised the manuscript and critically evaluated the intellectual contents. All authors have read and approved the content of the manuscript and confirmed the accuracy or integrity of any part of the work.

\section{Conflicts of interest}

The authors declare that there is no conflict of interest in this study.

\section{Ethical considerations}

Ethical subjects such as plagiarism and double publication have observed in this study.

\section{Funding/Support}

There is not any funding resource.

\section{References}

1. Sharfuddin A, Weisboard SD, Palevsky PM, Molitoris BA. Acute kidney injury. In: Brenner BM, editor. Brenner \& Rector's the Kidney. 9th ed. Philadelphia, PA: SaundersElsevier; 2012. p. 1045-69.

2. Jamme M, Mesnard L. Acute kidney injury by acute tubular necrosis. Rev Prat. 2018;68:156-9.

3. Dai B, Liu Y, Fu L, Li Y, Zhang J, Mei C. Effect of theophylline on prevention of contrast-induced acute kidney injury: a meta-analysis of randomized controlled trials. Am J Kidney Dis. 2012;60:360-70. doi: 10.1053/j.ajkd.2012.02.332.

4. Koch JA, Plum J, Grabensee B, Mödder U.Prostaglandin E1. a new agent for the prevention of renal dysfunction in high risk patients caused by radiocontrast media? PGE1 Study Group. Nephrol Dial Transplant 2000;15:43-9. doi: 10.1093/ ndt/15.1.43.

5. Chen HH, Anstrom KJ, Givertz MM, Stevenson LW, Semigran MJ, Goldsmith SR, et al. Low-dose dopamine or low-dose nesiritide in acute heart failure with renal dysfunction: the ROSE acute heart failure randomized trial. JAMA. 2013;310:2533-43. doi: 10.1001/jama.2013.282190.

6. Abd-Elkareem MI, Al Tamimy HM, Khamis OA, Abdellatif SS, Hussein MR. Increased urinary levels of the leukocyte adhesion molecules ICAM-1 and VCAM-1 in human lupus nephritis with advanced renal histological changes: preliminary findings. Clin Exp Nephrol. 2010;14(6):548-57. doi: 10.1007/s10157-010-0322-z.

7. Grino JM.BN 52021: a platelet activating factor antagonist for preventing post-transplant renal failure. A doubleblind, randomized study. The BN 52021 Study Group inRenal Transplantation.Ann Intern Med 1994;121:345-7. doi: 10.7326/0003-4819-121-5-199409010-00006

8. Chen YT, Chang FC, Wu CF, Chou YH, Hsu HL, Chiang $\mathrm{WC}$, et al. Platelet-derived growth factor receptor signaling activates pericyte-myofibroblast transition in obstructive and post-ischemic kidney fibrosis. Kidney Int. 2011;80:1170-81. doi: 10.1038/ki.2011.208.

9. Simmons MN, Subramanian V, Crouzet S, Haber GP,
Colombo JR, Ukimura O, et al. $\alpha$-Melanocyte stimulating hormone analogue AP214 protects against ischemia induced acute kidney injury in a porcine surgical model. J Urol. 2010;183:1625-9. doi: 10.1016/j.juro.2009.12.007

10. Baxter GM, Rodger RS. Doppler ultrasound in renal transplantation. Nephrol Dial Transplant. 1997;12:2449-51.

11. Irshad A, Ackerman S, Sosnouski D, et al. A review of sonographic evaluation of renal transplant complications. Curr Probl Diagn Radiol. 2008;37:67-79. doi: 10.1067/j. cpradiol.2007.06.001.

12. Liberati A, Altman DG, Tetzlaff J, et al. The PRISMA statement for reporting systematic reviews and metaanalyses of studies that evaluate healthcare interventions: explanation and elaboration. BMJ. 2009 Jul 21; 339:b2700. doi: $10.1136 / \mathrm{bmj} . \mathrm{b} 2700$

13. Centre for Reviews and Dissemination: Systematic reviews: CRD's 16 guidance for undertaking reviews in health care. York: University of York, 2009.

14. Ounissi M, Gargah T, Barbouch S, Boubaker K, Cherif $\mathrm{M}$, Bacha $\mathrm{MM}$, et al. Acute tubular necrosis in kidney transplantation. La Tunis Med. 2012;90(6):463-7.

15. Brophy D, Najarian JS, Kjellstrand CM. Acute tubular necrosis after renal transplantation. Transplantation. 1980;29(3):245-8.

16. Hall IE, Reese PP, Weng FL, Schröppel B, Doshi MD, Hasz $\mathrm{RD}$, et al. Preimplant histologic acute tubular necrosis and allograft outcomes. CJASN. 2014;9:573-582. doi: 10.2215/ CJN.08270813.

17. Ritz M, Botha J, Pontin AR, Pascoe MD, Kahn D. Does cyclosporine influence the outcome in patients with acute tubular necrosis after renal transplantation? Transplant Proc. 1999;31:303. doi: 10.1016/s0041-1345(98)01636-4

18. Gwinner W, Hinzmann K, Erdbruegger U, Scheffner I, Broecker V, Vaske B, et al. Acute tubular injury in protocol biopsies of renal grafts: prevalence, associated factors and effect on long-term function. Am J Transplant. 2008;8:168493. doi: 10.1111/j.1600-6143.2008.02293.x.

19. Hall I, Reese P, Weng F, Schroppel B, Doshi M, Hasz R, et al. Deceased kidney donor acute tubular necrosis and the development of delayed graft function. 2013; 13 (suppl 5).

20. Bagheri SM, Tajalli F, Shahrokh H, Nasiri Partovi M, Azadian N. Sonographic indices in patients with severe acute tubular necrosis during early post-kidney transplantation period. Int J Organ Transplant Med. 2019;10:74-83.

21. Toledo Pereyra-LH, Whitten JI. Compa $\neg$ rison of the incidence and effect of ATN in the cyclosporine and ALG eras. Transplant Proc. 1988;20:910-2.

22. Chung YC, Huang MT, Chang CN, Lee PH, Lee CS, Huang TW. Prolonged nonoliguric acute renal failure associated with high-dose vitamin $\mathrm{K}$ administration in a renal transplant recipient. Transplant Proc. 1994;26:2129-31.

23. Canadian Multicentre Transplant Study Group. A randomized clinical trial of cyclosporine in cadaveric renal transplantation. New Eng J Med. 1983;309:809-15. doi: 10.1056/NEJM198605083141904

24. Civantos DP, Cantero AM, Marcos MR, Seijas HF, Triviño MS, Frutos MP, et al. Utility of basal regional oximetry saturation for the diagnosis of acute tubular necrosis in the early postoperative period following kidney transplantation. Transplant Proc 2019;51:328-33. 
25. Chung YC, Lee PH, Hu RH. The outcome and delayed graft function in cadaveric renal transplants treated with low dose cyclosporine. J Formos Med Assoc. 1991;90:975-80.

26. Toussaint C, Kinnaert P, De Pauw L. Comparison of low doses of cyclosporine with azathioprine immunosuppression during the first year following transplantation. Transplant Proc. 1986;18:1256-8.

27. Ruggenenti P, Perico N, Mosconi L, Gaspari F, Benigni A, Amuchastegui CS, et al. Calcium channel blockers protect transplant patients from cyclosporine-induced daily renal hypoperfusion. Kidney Int. 1993;43(3):706-11. doi: 10.1038/ki.1993.101.

28. Palmer BF, Dawidson IN, Sagalowsky AR, Sandor ZS, Lu CY. Improved outcome of cadaveric renal transplantation due to calcium channel blockers. Transplantation. 1991; 52:640-5. doi: 10.1097/00007890-199110000-00012.
29. Rao KV, Kjellstrand CM. Post-transplant acute renal failure: a review. Clinical and experimental dialysis and apheresis. 1983;7:127-43.

30. Garcia TM, Abrão Cardeal da Costa J, Costa RS, Ferraz AS. Acute tubular necrosis in kidney transplant patients treated with enalapril. Ren Fail. 1994;16:419-23. doi: 10.3109/08860229409044882.

31. Qaqish SS, Zuckerman JE, Danovitch GM, Lum EL. Acute kidney injury in a patient following kidney transplantation. Am J Kidney Dis. 2019;73(1):A15-9. doi: 10.1053/j. ajkd.2018.09.007.

32. Mekeel KL, Moss AA, Mulligan DC, Chakkera HA, Hamawi K, Mazur MJ, Heilman RL, Reddy KS. Deceased donor kidney transplantation from donors with acute renal failure due to rhabdomyolysis. Am J Transplant. 2009;9:1666-70. doi: 10.1111/j.1600-6143.2009.02663.x.

Copyright (c) 2021 The Author(s); Published by Nickan Research Institute. This is an open-access article distributed under the terms of the Creative Commons Attribution License (http://creativecommons.org/licenses/by/4.0), which permits unrestricted use, distribution, and reproduction in any medium, provided the original work is properly cited. 